\title{
The Simple Life: On the Benefits of Low Self-Complexity
}

\author{
Allen R. McConnell \\ Laura M. Strain \\ Christina M. Brown \\ Miami University \\ Robert J. Rydell \\ Indiana University
}

This article examines the spillover amplification bypothesis, which proposes that because people lower in selfcomplexity experience stronger responses to life events they will show relatively better well-being in the presence of positive factors (e.g., better social support) and relatively poorer well-being in the presence of negative factors (e.g., a history of negative experiences). Across three studies, support for spillover amplification was found. Specifically, people lower in self-complexity revealed greater self-esteem, less depression, and fewer illnesses when they had greater social support (Study 1) and more desirable personality characteristics (Study 2), yet they had poorer well-being if they had a history of many negative life events (Study 3). Thus, how one's self-concept is represented in memory moderates the relationship between many well-established factors and well-being.

Keywords: self concept; self-complexity; well-being; social support; personality

$\mathrm{P}$ eople show considerable variability in their reactions to life's events. For instance, positive experiences (e.g., having close friends and family) seems to be especially beneficial for some more than for others. Similarly, negative experiences (e.g., enduring misfortunes such as natural disasters or divorces) affect some tremendously yet roll off the backs of others. Although there are many established factors (e.g., better social support, positive personality characteristics) that affect well-being, we propose that such relationships can be moderated by how the self is organized in memory.

Specifically, we examined how self-complexity qualifies relationships between well-being and three different factors: one's social support (Study 1), personality characteristics (Study 2), and past history of negative life occurrences
(Study 3). To understand how self-concept representation might serve this moderating role, one must first consider the organization of the self in memory and its implications. Most psychologists view the self as a collection of context-dependent selves (i.e., self-aspects) that can vary considerably in the attributes one reveals in each of these contexts (e.g., Baumeister, 1998; Linville \& Carlston, 1994). For example, one might possess several meaningful self-aspects (e.g., academic, athlete, pet owner) and reveal very different attributes in each of these self-aspects (e.g., driven as an academic but relaxed as a pet owner). Research on self-complexity captures these two features of self-concept representation: the number of self-aspects one has and the extent to which each self-aspect is relatively unique (i.e., shares few attributes with other selfaspects). People are considered greater in self-complexity when they have a relatively greater number of self-aspects comprised of relatively unique attributes (McConnell \& Strain, 2007; Rafaeli-Mor \& Steinberg, 2002).

\section{SELF-COMPLEXITY AS A MODERATOR: SPILLOVER AMPLIFICATION HYPOTHESIS}

Research has shown that people lower in self-complexity experience greater affective responses following self-relevant

Authors' Note: This work was supported by National Institute of Mental Health Grant MH068279, National Science Foundation Grant BCS 0601148, and the Lewis Endowed Professorship. Portions of this research were presented at the 19th and 20th annual Duck Conference on Social Cognition, Buck Island, NC. Address correspondence to Allen R. McConnell, Department of Psychology, Miami University, Oxford, OH 45056; e-mail: mcconnar@muohio.edu.

PSPB, Vol. 35 No. 7, July 2009 823-835

DOI: $10.1177 / 0146167209334785$

(C) 2009 by the Society for Personality and Social Psychology, Inc. 
feedback, with individuals receiving positive feedback revealing especially positive affect and people receiving negative feedback reporting especially negative affect (Linville, 1985). This "affective spillover" occurs more strongly for people lower in self-complexity because feedback about a particular self-aspect represents a larger proportion of their overall self-concept given that they have fewer self-aspects and because feedback concerning one self-aspect also implicates (i.e., spills over onto) other self-aspects that share attributes with the self-aspect implicated by the feedback. As a result, the organization of one's self-concept increases the impact of self-relevant feedback for people lower in selfcomplexity (McConnell, Rydell, \& Brown, in press). Additionally, people lower in self-complexity find it more difficult to get self-relevant events out of mind because their highly interconnected self-concept structures make mental regulation more difficult (e.g., attempts to ignore thoughts about a particular self-aspect often fail because other self-aspects share associative pathways), increasing the likelihood that one's experiences and related self-aspects remain accessible in memory (Renaud \& McConnell, 2002). Other research has shown that people lower in self-complexity reveal faster escape from aversive states of heightened self-awareness (Dixon \& Baumeister, 1991), poorer functioning following recent stressors (Linville, 1987), and greater reliance on their feelings in guiding their behaviors (Brown \& McConnell, in press).

Because of these consequences, one might wonder whether self-complexity has broader implications for well-being and health. Although some research has explored how people who vary in self-complexity deal with recent stress (e.g., Linville, 1987), this work considers how self-complexity might serve as a catalyst for long-standing psychological factors known to affect well-being. Our interest in this issue is based in part on findings revealing a small but reliable relationship between being lower in self-complexity and experiencing greater well-being (e.g., McConnell et al., 2005; Rafaeli-Mor \& Steinberg, 2002; Woolfolk, Novalany, Gara, Allen, \& Polino, 1995). We reasoned that enjoying relatively favorable life circumstances (often the case for undergraduate participants) might lead to greater well-being for people lower in self-complexity. Even though we did not investigate how recent stress translates into immediate outcomes as a function of selfcomplexity (cf. Linville, 1987), the current findings could well be qualified by factors such as recent stressful events (Cohen \& Wills, 1985). And although one may study well-being in a number of ways including happiness, positive affect, and negative affect (e.g., Diener, Eunkook, Lucas, \& Smith, 1999; Steel, Schmidt, \& Shultz, 2008), we focused on three outcomes studied extensively in the self-complexity literature (e.g., Linville, 1987; McConnell et al., 2005; Woolfolk et al., 1995): depression, physical illnesses, and self-esteem.

We anticipated that because people lower in selfcomplexity experience stronger responses to life events (e.g., Linville, 1985; Renaud \& McConnell, 2002), they would show stronger relationships between factors known to promote well-being (e.g., social support, positive personality characteristics) and outcomes such as self-esteem, depression, and physical illnesses for a number of reasons. First, because positive emotions help people deal with stress (Folkman \& Moskowitz, 2000) and lead to better well-being and health (Affleck \& Tennen, 1996), people whose self-concepts amplify positive experiences should benefit more strongly. Also, greater positive affect produces physiological-neuroendocrine responses that promote health (Taylor, Lerner, Sherman, Sage, \& McDowell, 2003) and support quick and effective recuperation from stressful episodes (Tugade \& Fredrickson, 2004). Moreover, positive mood improves self-regulation by reducing impulsive behaviors that can undercut healthy choices and effective stress management (Tice, Bratslavsky, \& Baumeister, 2001). And at an information-processing level, more positive affect initiates desirable outcomes ranging from greater long-range planning (e.g., Vallacher \& Wegner, 1987) to greater creativity in problem solving (e.g., Gasper, 2003). In sum, there are many reasons why positive affect improves well-being, and this should be especially true for people lower in self-complexity who experience more positive circumstances. Thus, we forward the "spillover amplification hypothesis," which posits that self-complexity will qualify a number of findings about factors associated with well-being, with those lower in self-complexity showing stronger relationships because the structure of their self-concepts will intensify and augment the accessibility of their life experiences and their impact on well-being.

\section{STUDY 1: SPILLOVER AMPLIFICATION FOR SOCIAL SUPPORT}

Numerous studies reveal that possessing greater social support improves psychological and physiological functioning (Harter, 2003; House, Landis, \& Umberson, 1988; Uchino, Cacioppo, \& Kiecolt-Glaser, 1996). In a meta-analysis of 81 studies, Uchino et al. (1996) found that greater social support has beneficial effects on the cardiovascular, endocrine, and immune systems. Also, House et al. (1988) found that poorer social support increases mortality rates even after biological and personality variables are statistically controlled. The benefits of social support are not solely related to physiological 
outcomes. For instance, perceived support from one's significant other is strongly and positively correlated to self-esteem ( $r \mathrm{~s}=.50$ to .65 ; Harter, 2003). Although research has found that the benefits of social support are stronger for women than for men (e.g., Nezlek, Wheeler, \& Reis, 1990), Uchino et al.'s review concluded that social support is beneficial for both men and women. Social support can benefit people by providing opportunities to experience greater enjoyment of life (Rook, 1987) and to have others as confidants (Pennebaker, 1997).

Study 1 explored the spillover amplification hypothesis by examining the extent to which self-concept representation moderates the relationship between greater social support and greater well-being. We expected to replicate past findings showing a positive relationship between social support and well-being. But more important, we predicted this relationship would be qualified by self-complexity, with this relationship being especially strong for people lower in self-complexity.

\section{Method}

\section{Participants}

At Michigan State University, 64 undergraduates (51 women, $13 \mathrm{men}$ ) participated in exchange for extra credit. They took part in two different sessions to collect data on their social support (beginning of the semester) and their self-complexity and well-being (several weeks later). The social support data were collected in a mass testing session (embedded in a packet of other prescreening measures) and the latter took place in the laboratory.

\section{Measures}

Social contact measures. Participants completed a number of questionnaires, each on its own page. Among these were three items (with filler items interspersed among them) to assess the quantity and quality of their social support. First, they were told to "please report the number of people with whom you can discuss meaningful issues (this can include friends, family, clergy, teachers, etc.)" on a blank line. Next, participants rated the quality of their social support on a scale ranging from 1 (poor) to 9 (ideal). Finally, they were asked "to consider your closest friend" and to indicate, using seven different Venn diagram figures, the extent to which they were close to their best friend (modeled after Aron, Aron, \& Smollan, 1992). Each diagram was associated with a number ranging from 1 (two adjacent circles with no overlap) to 4 (overlapping circles that passed through each other's center) to 7 (two circles that overlapped almost completely). Thus, larger values on each measure reflected greater social support. Although social support has been assessed in myriad ways (e.g., perceived quality of one key relationship, social network integration; see Cohen \& Wills, 1985; Gottlieb, 1983; Uchino et al., 1996), we used these three measures because they assess a range of social support indicators, were easily understood by our participants, and (in pretesting) they reliably predicted well-being.

Self-complexity task. Participants came to the laboratory and completed the remaining measures, which were administered by computer in private rooms (McConnell et al., 2005; Renaud \& McConnell, 2002). First they completed a self-complexity task that presented a list of 33 traits, which participants placed into groups that represented meaningful aspects of their lives (traits and instructions were those used by Linville, 1987). Using a computer interface, they selected the traits that they wanted to use for each self-aspect and provided a descriptive label for the self-aspect. Participants were told that they could use as many traits as they wanted for each self-aspect, could use any trait in multiple selfaspects, and did not have to use all of the traits provided. They were told to create as many self-aspects as were meaningful to them and to stop when generating new ones became difficult.

A self-complexity score was computed for each participant using Scott's (1969) $H$ statistic, which is the most widely used measure of self-complexity (RafaeliMor \& Steinberg, 2002). $H$ takes into account the number of self-aspects generated and the extent to which the traits that comprise those self-aspects are nonredundant with each other across self-aspects:

$$
H=\log _{2} n-\left(\Sigma_{\mathrm{i}} n_{\mathrm{i}} \log _{2} n_{\mathrm{i}}\right) / n,
$$

where $n$ is the total number of traits available to the participant (33 in this experiment) and $n_{\mathrm{i}}$ is the number of traits that occur within each particular group combination (i) across the self-aspects reported by the participant. ${ }^{1} H$ represents an index of the minimal number of independent binary combinations of traits needed to reproduce a participant's entire self-complexity sort (for extensive discussions, see Linville, 1987; Rafaeli-Mor, Gotlib, \& Revelle, 1999; Schleicher \& McConnell, 2005; Woolfolk et al., 1995).

Well-being measures. Following the self-complexity task and consistent with past work (e.g., McConnell et al., 2005), participants completed several measures of well-being. First, the Rosenberg (1965) Self-Esteem Scale assessed participant agreement with 10 statements (e.g., "I feel that I have a number of good qualities") on a scale ranging from 1 (strongly disagree) to 4 (strongly 
agree). The sum of the participants' responses (reversecoded for five items) was calculated, with larger scores indicating greater self-esteem.

Next, participants completed an inventory (Cohen \& Hoberman, 1983) of 39 common illnesses and physical symptoms (e.g., sleep problems, muscle cramps). For each item, they reported whether they had experienced it in the past 2 weeks (a score of 0 was recorded for symptoms not experienced), and for experienced symptoms they reported their severity on a scale ranging from 1 (not been a bother) to 5 (been an extreme bother). The sum of these responses served as the measure of physical symptoms.

Finally, participants completed the Beck Depression Inventory (Beck, Ward, Mendelson, Mock, \& Erbaugh, 1961) to assess depressed affect. The Beck Depression Inventory consists of 13 items where respondents choose one of four statements that vary in how strongly they represent depressed feelings (e.g., "I don't feel disappointed in myself," "I am disappointed in myself," "I am disgusted with myself," and "I hate myself"). Each response was scored using a scale ranging from 0 to 3 (larger values reflected greater severity), and the sum of these responses indicated reporting relatively greater depressed affect.

\section{Results}

Because our focus was on how having greater social support might produce especially greater well-being for people lower in self-complexity, we first evaluated whether our multiple measures of social support and of well-being could each be reduced. Reducing the data would provide more reliable estimates of social support and well-being, and it would simplify data presentation. Indeed, the three items assessing social support were related $(r s>.66$, $p s<.001)$, thus each item was standardized and the mean of those standardized scores was computed. ${ }^{2}$ Larger, positive scores on this social support variable reflected greater social support. Similarly, the three measures of well-being were related to each other $(r s>.41$, ps $<.001)$, and each item was standardized (depression and physical symptoms were reverse scored) and their mean indicated the extent to which each participant reported greater well-being. ${ }^{3}$ The observed self-complexity scores $(M=2.25, S D=0.87)$ were consistent with past work (McConnell \& Strain, 2007).

First, we replicated past findings showing that people lower in self-complexity reported greater well-being $(r=-.25, p<.05)$. As expected, people with greater social support also reported greater well-being $(r=.68$, $p<.001)$. Although we had no predictions about a direct relationship, self-complexity was unrelated to social support $(r=-.12, n s)$.

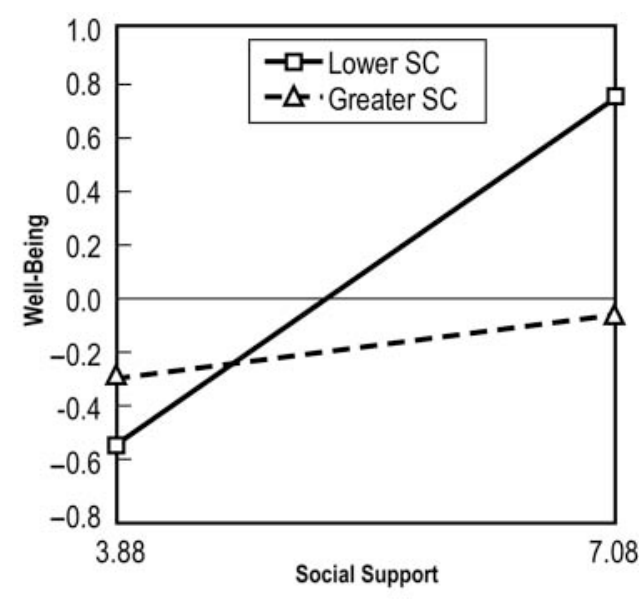

Figure 1 Interaction between social support and self-complexity in predicting well-being in Study 1.

Our key hypothesis was that the positive relationship between social support and well-being would be stronger for people lower in self-complexity. To test this prediction, we conducted a multiple regression analysis where well-being was regressed on self-complexity, social support, and their interaction (product term). In all regression analyses in this work, measures were centered such that each interaction term was orthogonal to its constituent variables (Aiken \& West, 1991). Although some predictor variables were correlated in this work, analyses of variance inflation factors indicated no evidence of multicollinearity in any of the three current studies. Variance inflation factors were low $(<2)$ and far below values that might indicate interpretation concerns (i.e., variance inflation factors $>10$; see Neter, Kutner, Nachtsheim, \& Wasserman, 1996).

The interaction regression analysis yielded two significant effects and one marginal effect. First, greater social support continued to make a unique contribution in predicting greater well-being $(\beta=1.20, t=4.22, p<.001)$. Second, the unique contribution of lower self-complexity in predicting greater well-being was now only marginally significant $(\beta=-0.16, t=1.79, p<.08)$. But of greatest importance was the predicted significant interaction between social support and self-complexity $(\beta=-0.34$, $t=2.14, p<.04){ }^{4}$

To illustrate this interaction, well-being was graphed using the nonstandardized regression coefficients plotting social support along the abscissa (with a range of $\pm 1 S D)$ and two lines, one representing relatively lower self-complexity (1 $S D$ below the mean) and the other representing relatively greater self-complexity (1 SD above the mean). As shown in Figure 1, we observed the specific interaction pattern predicted by the spillover 
amplification hypothesis. Specifically, well-being was better for people with greater social support, and this relationship was more pronounced for people with relatively lower in self-complexity.

\section{Discussion}

Study 1 replicated past work showing that people with greater social support enjoy greater well-being (e.g., House et al., 1988; Uchino et al., 1996). More important, this relationship was especially strong for people lower in self-complexity. That is, having a selfconcept structure that amplifies one's positive life experiences (in this case, greater social support) is especially beneficial. Study 1 also replicated the modest relationship between lower self-complexity and greater wellbeing, but as the predicted interaction reveals, this relationship was more characteristic of people with greater social support.

\section{STUDY 2: SPILLOVER AMPLIFICATION FOR PERSONALITY CHARACTERISTICS}

In addition to situational factors such as social support, personality characteristics relate to well-being (e.g., Leary \& MacDonald, 2003; Smith \& MacKenzie, 2006). In this study, we considered meaningful individual differences through the lens of the Five-Factor Model (FFM) of personality (John \& Srivastava, 1999; McCrae \& Costa, 1999; McCrae \& John, 1992), which classifies one's personality attributes using five relatively stable dimensions: extraversion versus introversion, agreeableness versus antagonism, conscientiousness versus lack of direction, neuroticism versus emotional stability, and openness versus closedness to experience.

Research has shown that these FFM dimensions predict well-being and overall happiness. For instance, Kwan, Bond, and Singelis (1997) found that greater life satisfaction was predicted by less neuroticism, greater extraversion, greater agreeableness, and greater conscientiousness. They also found that self-esteem was positively related to greater extraversion, openness to experience, and conscientiousness (see also, Halamandaris \& Power, 1997). In an overview, Robins, Tracy, Trzesniewski, Potter, and Gosling (2001) found evidence that each of the five factors could predict self-esteem. It is also worth noting that the FFM dimensions relate to important life outcomes. For example, being relatively greater in agreeableness, conscientiousness, and openness to experience predicts better classroom performance and reduced juvenile delinquency (e.g., John, Capsi, Robins, Moffitt, \& Stouthamer-Loeber, 1994), and better physical health in the near-term (e.g., Adams, Cartwright, Ostrove, \&
Stewart, 1998) and 40 years later (e.g., Hampson, Goldberg, Vogt, \& Dubanoski, 2006).

Thus, in this study, we explored the spillover amplification hypothesis with FFM personality traits. With respect to the predictions, a number of possibilities were considered. For example, because some personality factors (e.g., less neuroticism, greater conscientiousness) have been found to be stronger predictors of self-esteem than other factors (Robins et al., 2001), it may be that these factors are the most likely candidates to reveal spillover amplification. However, some relationships between personality factors and well-being may only be revealed after taking into account other moderating factors, such as self-concept representation. Thus, it is possible that personality factors that do not always show the strongest relationships with well-being could reveal spillover amplification once the moderating role of selfcomplexity is considered. In sum, we expected some personality factors to predict well-being (Kwan et al., 1997; Robins et al., 2001), and we were especially interested in whether self-complexity by personality factor interactions would indicate that the benefits of more desirable personality characteristics would be especially revealed by people lower in self-complexity (i.e., spillover amplification).

\section{Method}

\section{Participants}

At Miami University, 85 undergraduates (30 men, 55 women) participated to fulfill a research requirement. As in Study 1, they participated in two different sessions. At Session 1, participants completed a computeradministered study consisting of the self-complexity task and measures of the three well-being constructs assessed in Study 1. At the second session, they completed a number of questionnaires, including a measure of personality based on the FFM.

\section{Initial Session}

Participants completed a computer-based task similar to the one used in Study 1 with the following exceptions. First, the self-complexity task used in Study 2 provided 40 trait attributes, 20 positive and 20 negative (Showers, 1992). McConnell et al. (2005) demonstrated that both sets of traits (33 vs. 40) used in self-complexity research produce similar results. We used the larger trait set in this study to provide participants with a greater range of attributes to select for their self-complexity sorts. Following the self-complexity task, participants completed the same measures of self-esteem and physical symptoms used in Study 1. However, in this study, we replaced the Beck Depression Inventory with the Center 
for Epidemiologic Studies Depression Scale (Radloff, 1977) because it is potentially more sensitive to depressed affect in an undergraduate population. The Center for Epidemiologic Studies Depression Scale asks participants to endorse the extent to which they have experienced 20 different affect-related symptoms in the past 2 weeks (e.g., "I felt that everything I did was an effort") on a 4-point scale. The sum of participants' responses was calculated, with greater scores indicating more depressed affect.

\section{Personality Measure}

A 50-item version of Goldberg's (1999) adaptation of the NEO Personality Inventory-Revised (Costa \& McCrae, 1992) was used to assess participants' degree of openness (e.g., "I have a vivid imagination"), agreeableness (e.g., "I have a good word for everyone"), conscientiousness (e.g., "I am always prepared"), extraversion (e.g., "I make friends easily"), and neuroticism (e.g., "I have frequent mood swings"). This scale included 10 questions for each of the five personality factors, and participants indicated their agreement with each statement on a scale ranging from 1 (very inaccurate) to 5 (very accurate), with 3 as the midpoint (neither inaccurate or accurate). Half of the items for each personality factor were reverse scored. Greater scores for each of the five dimensions reflected a greater degree of its prevalence in the participant's personality.

\section{Results}

As in Study 1, the measures of self-esteem $(M=32.25$, $S D=4.61)$, physical symptoms $(M=25.01, S D=15.14)$, and depressed affect $(M=33.78, S D=8.33)$ were related to each other ( $r s>.37$, $p s<.001)$, and thus, as in Study 1, each scale was standardized and the mean was calculated to produce a single index where greater scores reflected greater well-being.

Replicating Study 1 and past findings, we observed a negative correlation between self-complexity $(M=2.70$, $S D=1.00)$ and well-being $(r=-.30, p<.01)$, with people lower in self-complexity experiencing greater well-being. Although we did not have any a priori predictions about the relationship between self-complexity and personality dimensions, we observed that greater self-complexity predicted more neuroticism $(r=.25, p<.03)$ and less agreeableness $(r=-.25, p<.03)$. There were no relationships between self-complexity and the other three personality factors. Also, individuals lower in neuroticism $(r=-.63, p<.001)$ and people greater in conscientiousness $(r=.26, p<.02)$ reported greater well-being.

Turning to the central analyses, we explored whether the relationship between personality characteristics and
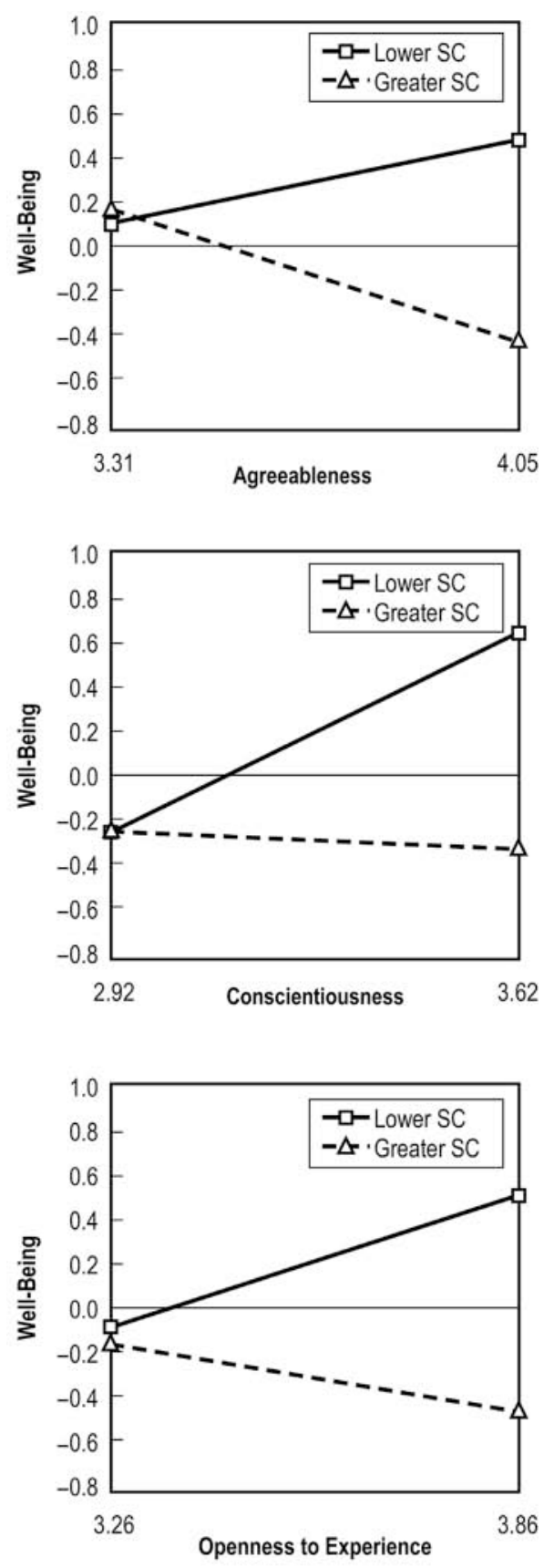

Figure 2 Interactions between personality characteristics (agreeableness, conscientiousness, and openness) and selfcomplexity in predicting well-being in Study 2.

well-being would be qualified by self-complexity. Accordingly, we conducted five different multiple regression analyses (one for each personality factor) where well-being was regressed on self-complexity, one of the five personality factors, and the interaction between self-complexity and that personality factor. The results of these analyses are presented in Table 1 . A number of 
TABLE 1: Standardized Regression Weights for Self-Complexity $x$ Personality Factor Interactions in Predicting Well-Being in Study 2

\begin{tabular}{lccc}
\hline & \multicolumn{3}{c}{ Standardized Regression Weights } \\
\cline { 2 - 4 } $\begin{array}{l}\text { Personality } \\
\text { Factor }\end{array}$ & $\begin{array}{c}\text { Self- } \\
\text { Complexity }\end{array}$ & $\begin{array}{c}\text { Personality } \\
\text { Factor }\end{array}$ & $\begin{array}{c}\text { Self-Complexity } \times \\
\text { Personality Factor }\end{array}$ \\
\hline Agreeableness & $-.24^{*}$ & $.64^{*}$ & $-.75^{*}$ \\
Conscientiousness & $-.28^{*}$ & $.97^{* *}$ & $-.78^{*}$ \\
Extraversion & $-.31^{*}$ & -.14 & .20 \\
Neuroticism & -.17 & $-.87^{* *}$ & .31 \\
Openness & & & \\
$\quad$ to experience & $-.30^{*}$ & $.72^{* *}$ & $-.63^{*}$ \\
\hline
\end{tabular}

$* p<.05 . * p<.01$.

findings are of interest. First, in four of the five analyses, self-complexity made a unique contribution in predicting well-being (i.e., lower self-complexity was associated with greater well-being). Second, in four of the five analyses, the personality characteristic evaluated was a significant predictor of well-being in the direction one would anticipate (i.e., greater well-being was associated with more agreeableness, more conscientiousness, less neuroticism, and more openness to experience). But most important for the spillover amplification hypothesis, the interaction between self-complexity and personality type in predicting well-being was found for three personality factors: agreeableness, conscientiousness, and openness to experience.

To illustrate these interactions, well-being was graphed using the nonstandardized coefficients plotting each relevant personality characteristic along the abscissa (range of $\pm 1 S D)$ and two lines, one representing relatively lower self-complexity (1SD below the mean) and the other representing relatively greater self-complexity $(1 S D$ above the mean). As each panel of Figure 2 reveals, the greatest differences in well-being as a function of selfcomplexity were exhibited for those individuals possessing the most desirable personality characteristics (i.e., more agreeableness, more conscientiousness, and more openness to experience). As anticipated by the spillover amplification hypothesis, well-being was especially high for people with the most favorable personality traits who were also relatively lower in self-complexity. ${ }^{5}$

\section{Discussion}

In Study 2, we explored the interplay of personality factors derived from the FFM and self-concept structure in predicting well-being. Most important, we found that self-complexity entered into meaningful interactions with three personality factors in predicting well-being, and the pattern of results was consistent with the spillover amplification hypothesis. Specifically, the greatest wellbeing was reported by people possessing relatively more agreeableness, more conscientiousness, and more openness to experience who were also lower in selfcomplexity (i.e., people whose self-concept structure amplifies the positivity of these desirable personality characteristics).

Because of somewhat inconsistent findings in the literature regarding what features of the FFM predict well-being, it was difficult to anticipate exactly which personality factors might reveal spillover amplification effects. In their overview of past work exploring relationships between FFM and self-esteem, Robins et al. (2001) observed some consistencies and some differences in the literature. First, they found that emotional stability (i.e., less neuroticism), extraversion, and conscientiousness were the strongest predictors of self-esteem, with openness to experience and agreeableness being less strongly correlated to self-esteem. Interestingly, although conscientious played a role in the spillover amplification hypothesis, neuroticism and extraversion did not. However, in our regression analyses, greater neuroticism was strongly related to poorer well-being, although self-complexity did not qualify this relationship. Thus it appears that neuroticism did possess enough meaningful variability to predict well-being but self-complexity was insufficient in moderating this relationship. Yet a more intriguing question involves the lack of a relationship between extraversion and well-being in this study. Although the relationship between well-being and extraversion is not as large as it is for neuroticism (e.g., Jackson \& Gerard, 1996; Robins et al., 2001), it is still a relatively reliable predictor in the literature (e.g., Keller, 1999; Kwan et al., 1997). One possibility for these inconsistencies is that this work conceptualized well-being as a combination of self-esteem, depression, and physical illnesses, whereas most work has focused exclusively on various measures of self-esteem. ${ }^{6}$

We would also acknowledge that some degree of caution should be considered when interpreting the analyses presented in Table 1 because they report on five different regression analyses. Conducting multiple analyses, of course, increases the chance of Type I error. That being said, these interpretational concerns apply to myriad studies in the literature as well. Readers should take comfort in seeing that many of the findings presented in Table 1 showing factors that predict well-being replicate other studies involving self-complexity (e.g., Study 1; Woolfolk et al., 1995) and the FFM (e.g., Kwan et al., 1997; Robins et al., 2001) as well.

In sum, Study 2 found that self-concept representation can moderate relationships between desirable personality characteristics and well-being. It is interesting that these three desirable personality factors (i.e., agreeableness, 
conscientiousness, and openness to experience) have been shown to predict meaningful behaviors and better physical health (e.g., Hampson et al., 2006; John et al., 1994) too. Thus, we believe self-concept structure plays an important role in how individual differences relate to well-being, and we anticipate that additional hidden relationships between personality and well-being might be uncovered by considering the role of self-concept structure.

\section{STUDY 3: SPILLOVER AMPLIFICATION FOR NEGATIVE LIFE OCCURRENCES}

As a final empirical investigation of the spillover amplification hypothesis, we examined how one's past history of negative life occurrences (NLOs) might relate to well-being differently as a function of self-complexity. People with greater NLOs (e.g., life threatening illnesses, sexual abuse) report poorer well-being later in life. For example, experiencing parental divorce (Amato \& Keith, 1991), natural disasters (Rubonis \& Bickman, 1991), threats of terrorism (Shamai \& Kimhi, 2006), nuclear power plant accidents (Havenaar, de Wilde, van den Bout, Drottz-Sjöberg, \& van den Brink, 2003), and childhood abuse (Kendall-Tackett, Williams, \& Finkelhor, 1993) all have a considerable impact on well-being. Not only do NLOs directly influence wellbeing but they can also impair factors that promote resiliency (e.g., eroding social support resources, reducing hardiness), which further diminishes well-being (Cohen, Kessler, \& Gordon, 1995).

In this study, we reasoned that the link between experiencing more NLOs and poorer well-being would be especially poignant for people lower in self-complexity for two reasons. First, affective spillover should increase the negativity associated with experiencing traumatic events, making the pain of experiencing them and reflecting on them especially unpleasant. And as previously noted, Renaud and McConnell (2002) found that people lower in self-complexity have greater difficulty in mental regulation (i.e., trying to not think about a negative selfaspect), producing stronger rebound effects because the structure of their self-concept makes avoiding unwanted thoughts especially difficult. Thus, both affective spillover and mental regulation failure should conspire to magnify the impact of NLOs for people lower in selfcomplexity. On the other hand, people with few NLOs who are lower in self-complexity should enjoy relatively better well-being because the positive benefits of a good life should be more strongly experienced by people whose self-concepts augment their positive impact.

In some ways, this prediction may seem similar to the buffering hypothesis forwarded by Linville (1987), who found that people greater in self-complexity fare better in the wake of recent stress. Indeed, the underlying rationale for both reveals commonalities. However, what makes this work different is that we are not exploring how recent stressful events are manifested in greater symptomology in the immediate future (Linville, 1987). Instead, this work is exploring how NLOs from one's more distant past affect current well-being without considering recent stressors. Thus, the current predictions provide a nice complement to the buffering hypothesis by proposing that self-concept representation moderates how NLOs from one's past continue to predict present-day well-being independent of recent stress.

Although this study cannot establish causal relationships (e.g., we cannot change one's past), it is possible that NLOs may lead people to strategically modify the structure of their self-concepts to minimize the negativity associated with significant, undesirable events. For example, Showers, Abramson, and Hogan (1998) proposed that people might adaptively alter self-concept representation in response to significant life stressors. In their study, Showers et al. focused on how one might increase the positive features of a relatively negative self-aspect. In contrast, it is also possible that one might respond not by changing the valence of self-concept content (though this is certainly possible) but, instead, by increasing their selfcomplexity (i.e., a change in self-concept structure, not content). If true, we might observe that people with a considerable number of NLOs earlier in their lives have greater self-complexity today. That is, in the face of many NLOs, people may strategically increase their selfcomplexity to dampen the negative spillover effects or to distract themselves from thoughts of these negative life episodes. If so, we should observe a correlation between more NLOs and greater self-complexity.

Finally, Study 3 provided an opportunity to demonstrate that lower self-complexity is not always beneficial. For example, Study 1 showed that greater social support was especially advantageous for people lower in selfcomplexity, and Study 2 found that desirable personality characteristics were especially positive for people lower in self-complexity. When considering these studies, one might anticipate that lower self-complexity should predict poorer outcomes for individuals with very poor social support or for people possessing very negative personality traits. However, it is likely that our nonclinical sample of reasonably well-adjusted college students limits the number of participants who exhibit especially low social support or extreme personality characteristics, which could explain why we did not see poorer well-being for people lower in self-complexity experiencing more negative circumstances. Thus in Study 3, we collected data from a larger sample to increase the likelihood that some participants would report a considerable 
number of NLOs. Therefore, we expected that spillover amplification should result in poorer outcomes for people lower in self-complexity with especially negative past histories. Finally, we acknowledge that relying on selfreported histories of NLOs could result in less than veridical accounts of one's past (e.g., some participants may be hesitant to report on past traumatic events). However, if participant bias leads to some underreporting of NLOs, observing the predicted interaction would be even more difficult to obtain.

\section{Method}

\section{Participants}

At Miami University, 339 undergraduates (129 men, 210 women) participated to fulfill a research requirement in a single experimental session.

\section{Procedure}

At individual computer cubicles, participants completed the same self-complexity task used in Study 2 followed by the same three measures of well-being (i.e., self-esteem, Center for Epidemiologic Studies Depression Scale, and physical symptoms). Next, they reported the extent to which they had experienced NLOs using a modified version of the questionnaire developed by McConnell et al. (2005, Study 2). The NLO questionnaire presents participants with 34 NLOs that were established through pretesting to be applicable to members of the subject population (e.g., experiencing a natural disaster, being the victim of sexual assault, experiencing an unwanted pregnancy, being assaulted with a weapon). Each item was presented on the computer monitor, and participants indicated whether they had ever experienced it. If they had, they indicated how closely it matched their experiences on a scale ranging from 1 (a little like my experiences) to 10 (exactly like my experiences). On average, participants reported experiencing 2.96 of the 34 events $(S D=3.24)$. To assess NLOs experiences with greater sensitivity, we calculated the sum of their 10-point scale ratings $(M=24.65, S D=19.98)$, with greater scores reflecting greater NLO experiences.

\section{Results}

As in the previous two studies, the three indexes of well-being were interrelated $(r s>.36, p s<.001)$, and thus the measures of self-esteem $(M=32.45, S D=$ 4.68), depression $(M=33.65, S D=9.13)$, and physical symptoms $(M=25.07, S D=14.74)$ were each standardized and combined (as in the previous studies) to reflect the extent to which participants reported greater wellbeing. The mean self-complexity score fell in between

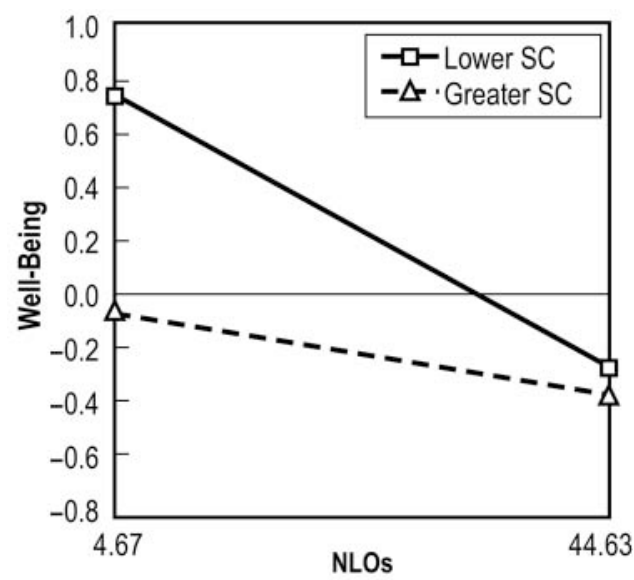

Figure 3 Interactions between negative life occurrences (NLOs) and self-complexity in predicting well-being in Study 3.

the values observed for the first two studies $(M=2.40$, $S D=0.94)$.

Replicating Studies 1 and 2, we observed that people lower in self-complexity reported greater well-being $(r=-.17, p<.01)$. There was also a modest but reliable correlation between self-complexity and NLOs $(r=.11$, $p<.05)$, indicating that individuals who experienced more NLOs also had relatively greater self-complexity. Also, as expected, people with greater NLOs had poorer well-being $(r=-.23, p<.001)$.

To examine the spillover amplification hypothesis, we evaluated whether the relationship between greater NLOs and poorer well-being was qualified by selfcomplexity. Thus, a multiple regression analysis regressed well-being on self-complexity, NLOs, and their interaction. All three predictors were significant. Specifically, lower self-complexity $(\beta=-.27, t=3.35, p<.001)$ and fewer NLOs $(\beta=-.21, t=3.98, p<.001)$ were unique predictors of greater well-being. More important for the spillover amplification hypothesis, there was a significant interaction between self-complexity and NLOs in predicting well-being $(\beta=.16, t=1.99, p<.05)$.

Figure 3 illustrates the pattern of this interaction using the nonstandardized coefficients, with well-being plotted on the ordinate and NLOs along the abscissa (range of $\pm 1 S D$ ) with two lines, one representing relatively lower self-complexity ( $1 S D$ below the mean) and the other depicting relatively greater self-complexity $(1 S D$ above the mean). Specifically, people with relatively fewer NLOs had better overall well-being than did people with more NLOs. However, the relationship between fewer NLOs and greater well-being was stronger for individuals whose self-complexity was relatively low. In other words, it was relatively more beneficial to be lower in 
self-complexity as one reported more positive life histories (i.e., fewer NLOs).

Recall that we predicted that for individuals with a large number of NLOs, being relatively lower in selfcomplexity should lead to poorer well-being. To test this expectation, we examined participants with extremely negative life histories (i.e., people whose NLOs were greater than $2 S D$ above the mean, $n=15$ ). Because the average participant had experienced relatively few of these events, it was important to examine people with the most NLOs to observe whether there would be a positive relationship between self-complexity and wellbeing for these individuals. Unlike the overall finding that lower self-complexity predicted greater well-being, the opposite relationship was found for the 15 individuals with the most NLOs. As expected, for people with the most negative life histories, lower self-complexity predicted poorer well-being $(r=.52, p<.05)$. Thus, for these individuals, lower self-complexity was associated with poorer outcomes, presumably due to affective amplification and their greater inability to control negative thoughts associated with these NLOs.

\section{Discussion}

Whereas the first two studies examined the spillover amplification hypothesis with respect to a situational factor (i.e., social support) and an individual difference factor (i.e., FFM of personality), respectively, this study examined how the relationship between one's past life history and well-being differs as a function of self-complexity. As predicted, people with fewer NLOs reported better well-being, and this relationship was especially pronounced for individuals lower in self-complexity. Although the average person experienced relatively greater well-being as they revealed lower self-complexity (replicating Studies 1 and 2), Study 3 found that people with especially negative life histories showed the opposite pattern of results. That is, for people with the most NLOs, people lower in self-complexity had poorer well-being. Thus, as one would anticipate from the spillover amplification hypothesis, lower self-complexity amplifies the relationship between particular features (e.g., positive or negative) and well-being.

We also observed an additional interesting finding that people with more NLOs had greater self-complexity. Although we cannot claim a causal relationship, this outcome is consistent with the position that people may strategically increase their self-complexity in response to NLOs to lessen their impact. Thus, similar to the proposal by Showers et al. (1998) that people might modify the content of their self-concept to address psychological vulnerabilities, this work suggests that people may amend the structure of their self-concept in the face of NLOs as well. In essence, one's self-concept may provide a flexible mechanism by which people manage negative events to mitigate their unwanted consequences.

\section{GENERAL DISCUSSION}

In this work, we showed that the nature of self-concept representation plays a moderating role in how personal and situational factors predict well-being. Three studies demonstrate how social support, personality traits, and life histories affect well-being differently as a function of self-complexity. We advanced a spillover amplification hypothesis, which proposes that self-complexity can serve as a moderator for well-established factors that predict well-being. Because people lower in self-complexity experience stronger responses, both affectively and memorially, to outcomes more so than do people greater in self-complexity (e.g., Linville, 1985; McConnell et al., in press; Renaud \& McConnell, 2002), they should be especially likely to show greater well-being when they have good social support (Study 1), when they possess desirable personality characteristics (Study 2), and when they have positive life histories (Study 3). On the other hand, people lower in self-complexity should reveal poorer well-being if they have a sufficiently negative life history (Study 3). In essence, when the structure of one's self-concept amplifies the intensity of life's experiences (i.e., being lower in self-complexity) and increases the extent to which experiences preoccupy one's mind, the correspondence between well-being and social support, personality traits, and life histories will be especially strong.

This spillover amplification hypothesis has several important implications. First, it suggests that a number of well-established findings in the literature, such as the concepts that greater social support is beneficial (e.g., Harter, 2003; House et al., 1988; Uchino et al., 1996), personality characteristics predict self-esteem and physical health (e.g., Hampson et al., 2006; John et al., 1994; Robins et al., 2001), and negative life occurrences have detrimental consequences (e.g., Amato \& Keith, 1991; Havenaar et al., 2003; Kendall-Tackett et al., 1993), exhibit meaningful variability as a function of self-complexity. In particular, these relationships hold more strongly for people lower in self-complexity. Not only does this work reveal a meaningful moderator for a number of literatures, it can provide a process account for how positive or negative experiences become amplified and thus influence well-being. The relatively simplified nature of how the self-concept is represented in memory for people lower in self-complexity increases the intensity of their life experiences and impairs their ability to successfully regulate their own thoughts, augmenting the influence of their experiences on psychological and physical functioning. And as past work reveals, greater feelings of 
positivity promote better health (e.g., Affleck \& Tennen, 1996; Taylor et al., 2003), stress management (e.g., Folkman \& Moskowitz, 2000; Tugade \& Fredrickson, 2004), and self-regulation (e.g., Tice et al., 2001). Thus, self-concept representation provides a mechanism through which positive and negative events have an especially strong impact on people's well-being.

It is intriguing that many literatures exhibiting important implications for well-being have not fully considered the structure of how the self is represented in memory. For instance, personality researchers often focus on the self in terms of its content (i.e., the personality traits people possess), but there may be additional insights gained by thinking about the interrelations of trait attributes within the context of an individual's idiosyncratic network of self-aspects. Indeed, people may reveal somewhat different personality profiles when different self-aspects are activated, and even at times, the activation of a particular self-aspect can even eliminate the accessibility of one's chronic attributes (Brown \& McConnell, 2009). One could imagine that assessing undergraduate participants in university laboratory settings means that their responses on personality measures overrepresent their student self-aspects relative to other self-aspects. As a result, it may be important to consider how the accessibility of particular self-aspects influences both the assessment of personality as well as the behavioral outcomes researchers wish to predict. This line of thinking anticipates not only that key personality traits will be important to the individual but that these traits may be context-specific in their influence (Mischel \& Shoda, 1995), especially for people greater in self-complexity (Brown \& McConnell, 2009).

In addition to demonstrating that people lower in selfcomplexity can benefit from their positive circumstances, this work reveals the double-edged sword of low selfcomplexity. For people lower in self-complexity, having the good life will result in positive outcomes whereas suffering through many traumatic events will be especially harmful. This observation may explain the small but reliable relationship between lower self-complexity and greater well-being observed in a number of studies (see Rafaeli-Mor \& Steinberg, 2002), including those presented here. That is, it is quite likely that most college students (the typical participants in these studies) have, on average, relatively positive lives. And because of spillover amplification, typical college students who are lower in self-complexity show greater well-being.

Furthermore, this research provides some suggestive evidence that one's self-concept might respond adaptively to negative life occurrences (Showers et al., 1998). Specifically, people with the most negative life histories showed greater self-complexity. Although no definitive claims can be made at present, these findings suggest that additional work should explore the possibility of an adaptive self-concept in greater detail, perhaps by using a longitudinal design to see if people encountering negative events find ways to increase self-complexity to mitigate the undesirable impact of these events.

In addition to its implications for existent literatures that predict well-being, the spillover amplification hypothesis contributes to research focused on self-concept representation. For instance, it provides a novel demonstration of the consequences of self-complexity. That is, this work establishes that self-complexity could serve as a catalyst for how long-standing factors (e.g., social support, personality), in addition to recent stressors (e.g., Linville, 1987), influence well-being. Thus, this work opens the door to a number of second-order effects where self-complexity combines with other situational, individual difference, and historical factors in shaping one's experiences. For example, people lower in selfcomplexity may show stronger dissonance-induced attitude change following counterattitudinal advocacy (e.g., Cooper \& Fazio, 1984), greater information search when in a negative mood (e.g., Schwarz \& Clore, 1996), or greater efforts to reduce self-discrepancies (e.g., Higgins, 1997) because the nature of their self-concepts "increase the signal" of affect, positive or negative. Related to this last point, recent work in our lab found that people who are lower in self-complexity are more likely to escape or expend greater effort following failure based on whether they view additional efforts as unlikely or likely (respectively) to produce improvement (Brown \& McConnell, in press). Indeed, a number of such second-generation questions can be pursued, not only taking into account the greater affective reactivity of people lower in self-complexity but also in considering a framework for thinking about how self-concept representation plays a role in these self-implicating phenomena. In sum, as this work illustrates, thinking more fully about selfconcept representation provides new insights on when the simple life is especially good to live.

\section{NOTES}

1. A group combination refers to traits that are uniquely associated with a specific combination of self-aspects. As an example, consider a participant who produces three self-aspects in a self-complexity task and that a particular trait appears in two of those self-aspects (e.g., in 1 and 2 but not 3). This trait would be identified as a member of the group combination 1-2. In this example, each of the 33 available traits could be associated with just one of the following group combinations: $1,2,3,1-2,1-3,2-3,1-2-3$, or the $\varnothing$ group (i.e., those traits not used at all in the sort task). In this example, there would be 8 possible group combinations (i) with $n_{\mathrm{i}}$ traits associated with each combination. Thus, the number of potential group combinations increases as more selfaspects are generated (e.g., adding a fourth self-aspect would increase the total number of potential group combinations from 8 to 16) and as the traits used in those self-aspects are uniquely associated (i.e., nonredundant) with particular group pairing combinations.

2. Because of the potential interest in gender effects in the social support literature (e.g., Nezlek, Wheeler, \& Reis, 1990; cf. Uchino, 
Cacioppo, \& Kiecolt-Glaser, 1996), we examined whether there were any gender differences on our measures. There was evidence that women had more close friends $(M=5.49, S D=1.84)$ than men did $(M=4.36, S D=1.61), t(62)=1.98, p<.06$ (overall $M=5.26, S D=$ 1.84). However, there was no evidence of sex effects on the other two measures of social support, quality of social support $(M=5.78, S D=$ $1.72)$, best friend closeness $(M=5.39, S D=1.27)$, or on the combined measure of social support, $t \mathrm{~s}<1.20, n s$. Similarly, there were no sex effects on measures of well-being or self-complexity, $t$ s $<1.30$, $n s$. Across all three studies, gender did not qualify any of the results, and thus it receives no further discussion.

3. Analyses examining each well-being measure separately (selfesteem $M=32.08, S D=5.22$; physical symptoms $M=21.34, S D=$ 17.01; Beck Depression Inventory $M=4.41, \mathrm{SD}=4.69$ ) revealed similar results.

4. In addition to $H$, there are alternative measures of self-complexity (Koch \& Shepperd, 2004), including measures of the number of selfaspects (NASPECTS) and attribute overlap (OL; Rafaeli-Mor, Gotlib, \& Revelle, 1999), and separate complexity indexes based on one's positive (+SC) and negative (-SC) attributes (e.g., Gara et al., 1993; Woolfolk, Novalany, Gara, Allen, \& Polino, 1995). In this work, we explored the potential role of each of these four alternative measures to account for the reported findings involving $H$. For example, perhaps a particular self-complexity subcomponent (e.g., attribute overlap, the complexity of one's negative self-concept attributes) might account for the current results. In Study $1, H$ was positively related to each of the four alternative self-complexity measures, $r \mathrm{~s}>.45$, $p s<.001$ (and it was positively related in all three studies, $p s<.001$ ). However, in no case did any of the four alternative measures reveal an interaction with social support in predicting well-being. In other words, in Study 1, there appears to be something important about considering both the number of self-aspects and attribute overlap, and there also appears to be something important about considering both positive and negative attributes in self-complexity rather than viewing a particular subcomponent of self-complexity as critical for the observed interaction between self-complexity and social support. We conducted similar analyses in Studies 2 and 3. Although occasionally these alternatives measures did show interactions similar to $H$, the pattern of results was far less consistent than it was with $H$.

5. To explore the potential unique contributions of the personality dimensions involved in interactions with $H$, a single analysis simultaneously regressed well-being on $H$, agreeableness and its interaction with $H$, conscientiousness and its interaction with $H$, and openness to experience and its interaction with $H$. None of the variables made a unique contribution, which seems to reflect relationships between the Five-Factor Model (FFM) dimensions (i.e., agreeableness predicted openness to experience $r=.26, p<.02$; conscientiousness predicted openness to experience, $r=-.37, p<.01)$. In this work, our interest was not in the unique predictive capacity of FFM dimensions but rather in exploring how chronic circumstances (instantiated by the FFM) predict well-being differently as a function of self-complexity.

6. Because our measures of well-being were highly intercorrelated, examining different patterns of correlations between personality factors and our three measures of well-being independently should not be overinterpreted. However, given the interest in self-esteem as the primary criterion measure in the personality literature, we note that our measure of extraversion showed a nonreliable correlation with selfesteem consistent with the past literature, $(r=.15, p>.17)$. As observed with our composite measure of well-being, greater self-esteem (examined alone) was reliably predicted by less neuroticism $(r=-.44$, $p<.001)$ and by greater conscientiousness $(r=.24, p<.03)$.

\section{REFERENCES}

Adams, S. H., Cartwright, L. K., Ostrove, J. M., \& Stewart, A. J. (1998). Psychological predictors of good health in three longitudinal samples of educated midlife women. Health Psychology, $17,412-420$.
Affleck, G., \& Tennen, H. (1996). Construing benefits from adversity: Adaptational significance and dispositional underpinnings. Journal of Personality, 64, 899-922.

Aiken, L. S., \& West, S. G. (1991). Multiple regression: Testing and interpreting interactions. Newbury Park, CA: Sage.

Amato, P. R., \& Keith, B. (1991). Parental divorce and the well-being of children: A meta-analysis. Psychological Bulletin, 110, 26-46.

Aron, A., Aron, E. N., \& Smollan, D. (1992). Inclusion of Other in the Self Scale and the structure of interpersonal closeness. Journal of Personality and Social Psychology, 63, 596-612.

Baumeister, R. F. (1998). The self. In D. T. Gilbert, S. T., Fiske, \& G. Lindzey (Eds.), Handbook of social psychology (4th ed., Vol. 1, pp. 680-740). New York: McGraw-Hill.

Beck, A. T., Ward, C. H., Mendelson, M., Mock, J., \& Erbaugh, J. (1961). An inventory for measuring depression. Archives of General Psychiatry, 4, 561-571.

Brown, C. M., \& McConnell, A. R. (2009). When chronic isn't chronic: The moderating role of active self-aspects. Personality and Social Psychology Bulletin, 35, 3-15.

Brown, C. M., \& McConnell, A. R. (in press). Effort or escape: Selfconcept structure determines self-regulatory behavior. Self and Identity.

Cohen, S., \& Hoberman, H. M. (1983). Positive events and social supports as buffers of life change stress. Journal of Applied Social Psychology, 13, 99-125.

Cohen, S., Kessler, R. C., \& Gordon, L. U. (1995). Strategies for measuring stress in studies of psychiatric and physical disorders. In S. Cohen, R. C. Kessler, \& L. U. Gordon (Eds.), Measuring stress: A guide for health and social scientists (pp. 3-26). New York: Oxford University Press.

Cohen, S., \& Wills, T. A. (1985). Stress, social support, and the buffering hypothesis. Psychological Bulletin, 98, 310-357.

Cooper, J., \& Fazio, R. H. (1984). A new look at dissonance theory. In L. Berkowitz (Ed.), Advances in experimental social psychology (Vol. 17, pp. 229-266). Orlando, FL: Academic Press.

Costa, P. T., \& McCrae, R. R. (1992). Four ways five factors are basic. Personality and Individual Differences, 13, 653-665.

Diener, E., Eunkook, M. S., Lucas, R. E., \& Smith, H. L. (1999). Subjective well-being: Three decades of progress. Psychological Bulletin, 125, 276-302.

Dixon, T. M., \& Baumeister, R. F. (1991). Escaping the self: Moderating effects of self-complexity. Personality and Social Psychology Bulletin, 17, 363-368.

Folkman, S., \& Moskowitz, J. T. (2000). Positive affect and the other side of coping. American Psychologist, 55, 647-654.

Gara, M. A., Woolfolk, R. L., Cohen, B. D., Goldston, R. B., Allen, L. A., \& Novalany, J. (1993). Perception of self and other in major depression. Journal of Abnormal Personality, 102, 93-100.

Gasper, K. (2003). When necessity is the mother of invention: Mood and problem solving. Journal of Experimental Social Psychology, 39, 248-262.

Goldberg, L. R. (1999). A broad-bandwidth, public-domain, personality inventory measuring the lower-level facets of several fivefactor models. In I. Mervielde, I. Deary, F. De Fruyt, \& F. Ostendorf (Eds.), Personality psychology in Europe (Vol. 7; pp. 7-28). Tilburg, the Netherlands: Tilburg University Press.

Gottlieb, B. H. (1983). Social support as a focus for integrative research in psychology. American Psychologist, 38, 278-287.

Halamandaris, K. F., \& Power, K. G. (1997). Individual differences, dysfunctional attitudes, and social support: A study of the psychosocial adjustment to university life of home students. Personality and Individual Differences, 22, 93-104.

Hampson, S. E., Goldberg, L. R., Vogt, T. M., \& Dubanoski, J. P. (2006). Forty years on: Teachers' assessments of children's personality traits predict self-reported health behaviors and outcomes at midlife. Health Psychology, 25, 57-64.

Harter, S. (2003). The development of self-representations during childhood and adolescence. In M. R. Leary \& J. P. Tangney (Eds.), Handbook of self and identity (pp. 610-642). New York: Guilford.

Havenaar, J. M., de Wilde, E. J., van den Bout, J., Drottz-Sjöberg, B. M., \& van den Brink, W. (2003). Perception of risk and subjective health among victims of the Chernobyl disaster. Social Science and Medicine, 56, 569-572. 
Higgins, E. T. (1997). Beyond pleasure and pain. American Psychologist, 52, 1280-1300.

House, J. S., Landis, K. R., \& Umberson, D. (1988). Social relationships and health. Science, 241, 540-545.

Jackson, L. A., \& Gerard, D. A. (1996). Diurnal types, the "Big Five" personality factors, and other personal characteristics. Journal of Social Behavior and Personality, 11, 273-283.

John, O. P., Caspi, A., Robins, R. W., Moffitt, T. E., \& StouthamerLoeber, M. (1994). The "little five": Exploring the nomological network of the five-factor model of personality in adolescent boys. Child Development, 65, 160-178.

John, O. P., \& Srivastava, S. (1999). The Big Five trait taxonomy: History, measurement, and theoretical perspectives. In L. A. Pervin and O. P. John (Eds.), Handbook of personality: Theory and research (2nd ed., pp. 102-138). New York: Guilford.

Keller, T. (1999). Images of the familiar: Individual differences and implicit leadership theories. Leadership Quarterly, 10, 589-607.

Kendall-Tackett, K. A., Williams, L. M., \& Finkelhor, D. (1993). Impact of sexual abuse on children: A review and synthesis of recent empirical studies. Psychological Bulletin, 113, 164-180.

Koch, E. J., \& Shepperd, J. A. (2004). Is self-complexity linked to better coping? A review of the literature. Journal of Personality, 72, 727-760

Kwan, V. S. Y., Bond, M. H., \& Singelis, T. M. (1997). Pancultural explanations for life satisfaction: Adding relationship harmony to self-esteem. Journal of Personality and Social Psychology, 73, 1038-1051.

Leary, M. R., \& MacDonald, G. (2003). Individual differences in selfesteem: A review and theoretical integration. In M. R. Leary \& J. P. Tangney (Eds.), Handbook of self and identity (pp. 401-418). New York: Guilford.

Linville, P. W. (1985). Self-complexity and affective extremity: Don't put all of your eggs in one cognitive basket. Social Cognition, 3, 94-120.

Linville, P. W. (1987). Self-complexity as a cognitive buffer against stress-related illness and depression. Journal of Personality and Social Psychology, 52, 663-676.

Linville, P. W., \& Carlston, D. E. (1994). Social cognition perspective on self. In P. G. Devine, D. L. Hamilton, \& T. M. Ostrom (Eds.), Social cognition: Contributions to classic issues in social psychology (pp. 143-193). New York: Springer-Verlag.

McConnell, A. R., Renaud, J. M., Dean, K. K., Green, S. P., Lamoreaux, M. J., Hall, C. E., \& Rydell, R. J. (2005). Whose self is it anyway? Self-aspect control moderates the relation between self-complexity and well-being. Journal of Experimental Social Psychology, 41, 1-18.

McConnell, A. R., Rydell, R. J., \& Brown, C. M. (in press). On the representation of self-concept: How self-concept organization influences affective responses and self-evaluations. Journal of Experimental Social Psychology.

McConnell, A. R., \& Strain, L. M. (2007). Content and structure of the self-concept. In C. Sedikides \& S. Spencer (Eds.), The self in social psychology (pp. 51-73). New York: Psychology Press.

McCrae, R. R., \& Costa, P. T. (1999). A five-factor theory of personality. In L. A. Pervin \& O. P. John (Eds.), Handbook of personality: Theory and research (pp. 139-153). New York: Guilford.

McCrae, R. R., \& John, O. P. (1992). An introduction to the five-factor model and its applications. Journal of Personality, 54, 430-446.

Mischel, W., \& Shoda, Y. (1995). A cognitive-affective system theory of personality: Reconceptualizing situations, dispositions, dynamics, and invariance in personality structure. Psychological Review, 102, 246-268.

Neter, J., Kutner, M. H., Nachtsheim, C. J., \& Wasserman, W. (1996). Applied linear statistical models (4th ed.). Chicago: Irwin.

Nezlek, J. B., Wheeler, L., \& Reis, H. (1990). Academic performance and social behavior. Journal of Social and Personal Relationships, 7,291-309.

Pennebaker, J. W. (1997). Opening up: The healing power of expressing emotions. New York: Guilford.
Radloff, L. S. (1977). The CES-D Scale: A self-report depression scale for research in the general population. Applied Psychological Measurement, 1, 385-401.

Rafaeli-Mor, E., Gotlib, I. H., \& Revelle, W. (1999). The meaning and measurement of self-complexity. Personality and Individual Differences, 27, 341-356.

Rafaeli-Mor, E., \& Steinberg, J. (2002). Self-complexity and well-being: A review and research synthesis. Personality and Social Psychology Review, 6, 31-58.

Renaud, J. M., \& McConnell, A. R. (2002). Organization of the selfconcept and the suppression of self-relevant thoughts. Journal of Experimental Social Psychology, 38, 79-86.

Robins, R. W., Tracy, J. L., Trzesniewski, K., Potter, J., \& Gosling, S. D. (2001). Personality correlates of self-esteem. Journal of Research in Personality, 35, 463-482.

Rook, K. S. (1987). Social support versus companionship: Effects on life stress, loneliness, and evaluations by others. Journal of Personality and Social Psychology, 52, 1132-1147.

Rosenberg, M. (1965). Society and the adolescent self-image. Princeton, NJ: Princeton University Press.

Rubonis, A. V., \& Bickman, L. (1991). Psychological impairment in the wake of disaster: The disaster-psychopathology relationship. Psychological Bulletin, 109, 384-399.

Schleicher, D. J., \& McConnell, A. R. (2005). The complexity of selfcomplexity: An Associated Systems Theory approach. Social Cognition, 23, 387-416.

Schwarz, N., \& Clore, G. L. (1996). Feelings and phenomenal experiences. In E. T. Higgins \& A. W. Kruglanski (Eds.), Social psychology: Handbook of basic principles (pp. 433-465). New York: Guilford.

Scott, W. A. (1969). Structure of natural cognitions. Journal of Personality and Social Psychology, 12, 261-278.

Shamai, M., \& Kimhi, S. (2006). Exposure to threat of war and terror, political attitudes, stress, and life satisfaction among teenagers in Israel. Journal of Adolescence, 29, 165-176.

Showers, C. (1992). Compartmentalization of positive and negative self-knowledge: Keeping bad apples out of the bunch. Journal of Personality and Social Psychology, 62, 1036-1049.

Showers, C., Abramson, L. Y., \& Hogan, M. E. (1998). The dynamic self: How the content and structure of the self-concept change with mood. Journal of Personality and Social Psychology, 75, 478-493.

Smith, T. W., \& MacKenzie, J. (2006). Personality and risk of physical illness. Annual Review of Clinical Psychology, 2, 435-467.

Steel, P., Schmidt, J., \& Shultz, J. (2008). Refining the relationship between personality and subjective well-being. Psychological Bulletin, 134, 138-161.

Taylor, S. E., Lerner, J. S., Sherman, D. K., Sage, R. M., \& McDowell, N. K. (2003). Are self-enhancing cognitions associated with healthy or unhealthy biological profiles? Journal of Personality and Social Psychology, 85, 605-615.

Tice, D. M., Bratslavsky, E., \& Baumeister, R. F. (2001). Emotional distress regulation takes precedence over impulse control: If you feel bad, do it! Journal of Personality and Social Psychology, 80, 53-67.

Tugade, M. M., \& Fredrickson, B. L. (2004). Resilient individuals use positive emotions to bound back from negative emotional experiences. Journal of Personality and Social Psychology, 86, 320-333.

Uchino, B. N., Cacioppo, J. T., \& Kiecolt-Glaser, J. K. (1996). The relationship between social support and physiological processes: A review with emphasis on underlying mechanisms and implications for health. Psychological Bulletin, 119, 488-531.

Vallacher, R. R., \& Wegner, D. M. (1987). What do people think they're doing? Action identification and human behavior. Psychological Review, 94, 3-15.

Woolfolk, R. L., Novalany, J., Gara, M. A., Allen, L. A., \& Polino, M. (1995). Self-complexity, self-evaluation, and depression: An examination of form and content within the self-schema. Journal of Personality and Social Psychology, 68, 1108-1120.

Received March 10, 2008

Revision accepted January 20, 2009 